\title{
Evaluating four -variable screening tool in european population of a sleep clinic for assessing obstructive sleep apnea syndrome
}

\author{
Athanasia Pataka', Seraphim Kotoulas², Evdokia Sourla², Sofia Akritidou², Evangelia Panagiotidou², \\ George Kalamaras ${ }^{3}$, Katalin Fekete ${ }^{4}$, Paraskevi Argyropoulou ${ }^{5}$
}

${ }^{1}$ Assitant Professor of Respiratory Medicine, Medical School, Aristotle University of Thessaloniki, Respiratory Failure Unit, G. Papanikolaou Hospital, 57010 Exohi, Thessaloniki, Greece, ${ }^{2}$ Resident in Respiratory Medicine, Respiratory Failure Unit, G. Papanikolaou Hospital,

Thessaloniki, Greece, ${ }^{3}$ Sleep technician Respiratory Failure Unit, G. Papanikolaou Hospital, Thessaloniki, Greece, ${ }^{4}$ Pulmonologist, Respiratory Failure Unit, G. Papanikolaou Hospital, Thessaloniki, Greece, ${ }^{5}$ Professor of Respiratory Medicine, Respiratory Failure Unit, Aristotle University of Thessaloniki, G. Papanikolaou Hospital, Thessaloniki, Greece

\section{A B S T R A C T}

Background: Different questionnaires have been used to evaluate patients with Obstructive sleep apnea/hypopnea syndrome (OSAHS). The 4-Variable screening tool (4-V) was developed and validated in Asian population for identifying moderate to severe OSAHS. Aims and Objectives: To evaluate the ability of $4-\mathrm{V}$ to identify patients at high risk for OSAHS in a European Population visiting a Sleep Clinic. Methods: 1057 (73.8\% males), $52 \pm 14$ years, BMI $33 \pm 7 \mathrm{~kg} / \mathrm{m}^{2}$, Epworth Sleepiness Scale (ESS) $11.5 \pm 5.4$ and Apnea Hypopnea Index (AHI) $32.7 \pm 26.5$ were included. All patients had an in laboratory sleep study and 4-V was calculated. Results: The mean 4-V score was $13.3 \pm 2.5$. Sensitivities of $4-\mathrm{V} \geq 11$ for $\mathrm{AHI} \geq 5, \geq 15$ and $\geq 30$ were $78 \%, 79 \%$ and $81 \%$, respectively; specificities 40.8\%, 36\%, 32\%; positive predictive values (PPV) $84.3 \%, 71 \%, 52 \%$; negative predictive values (NPV) $31 \%, 46.5 \%, 65 \%$ and area under the ROC curve at $\mathrm{AHI} \geq 15$ was 0.58 . For $4-\mathrm{V} \geq 14$, sensitivities for $\mathrm{AHI} \geq 5, \geq 15$ and $\geq 30$ were $50.7 \%, 55 \%$ and $61 \%$, respectively; specificities 78\%, 74.4\%, 69\%; PPV 90.3\%, 81\%, 64\%; NPV 27.9\%, 45\%, 66\% and area under the ROC curve at $\mathrm{AHI} \geq 15$ was 0.68 . The $4-\mathrm{V}$ differed significantly between no and mild and between moderate and severe OSAHS, but not between mild and moderate OSAHS in both genders. Sensitivity was better in men, but specificity was higher in women. Conclusion: In Caucasians the 4-V $\geq 14$ had low sensitivity and NPV, rather good specificity and PPV. For a cut-off $\geq 11$, sensitivity was better but specificity was low. However the predictive values differed between genders.

Access this article online Website:

http://nepjol.info/index.php/AJMS DOI: 10.3126/ajms.v7i2.13075 E-ISSN: 2091-0576 P-ISSN: $2467-9100$

Key words: 4-Variable screening tool, ESS, Evaluation, Sleep apnea, Sleep clinic

\section{INTRODUCTION}

Obstructive sleep apnea hypopnea syndrome (OSAHS) prevalence among middle-aged population ranges from $2-9 \%{ }^{1}$ and has been recognized as an important cause of morbidity and mortality as it is associated with a wide range of medical consequences (hypertension, cardiovascular diseases, psychological effects) and accidents. ${ }^{2,3}$ Polysomnography (PSG) has been used as the gold standard for OSAHS diagnosis but is time consuming and expensive. Different clinical models and questionnaires have been used to evaluate patients with the highest OSAHS probability in order to save time and money. The ideal screening test should be inexpensive, simple, non time consuming, with high sensitivity in order to detect patients with OSAHS early in the disease process and with sufficient specificity to eliminate unnecessary testing. ${ }^{4-8}$ Such a screening tool would greatly assist clinicians and researchers in the investigation and treatment of OSAHS. 
The 4-Variable screening tool (4-V) was developed and validated in Japan from Takegami et $\mathrm{al}^{5}$ as a tool for the identification of moderate to severe sleep-disordered breathing (SDB) with the knowledge of only 4 easily ascertainable variables (gender, blood pressure (BP) level, body mass index (BMI) and self-reported snoring). It has been found that the phenotype of OSAHS is influenced by race, with Asians with OSAHS having greater restriction in skeletal measurements and Caucasians being more obese. The aim of our study was to evaluate the ability of the 4-V to identify the patients with higher risk of OSAHS as measured by Apnea Hypopnea Index (AHI) in Caucasian Population visiting a Sleep Clinic.

\section{MATERIALS AND METHODS}

The data of the patients visiting the Sleep Clinic of the Respiratory Failure Unit of G Papanikolaou Hospital from 2009 to 2012 were retrospectively studied. The ethics committee reviewed and approved the protocol and did not require patient consent. Patients $>18$ years, referred for the evaluation of a possible sleep disorder who underwent inlaboratory polysomnography were included. Patients with previous diagnosis of OSAHS or another sleep disorder as narcolepsy, Continuous Positive Airway Pressure (CPAP) use or missing data were excluded. Sleepiness was evaluated with the Epworth Sleepiness Scale (ESS). ESS is a self-administered questionnaire for measuring subjective daytime sleepiness (8 questions). Scores above 10 are considered as abnormal sleepiness. ${ }^{6,7} \mathrm{BMI}$, age, neck circumference, gender and sitting BP were documented from a sleep technician.

The $4-\mathrm{V}^{5}$ consists of four variables (gender, BP, BMI and self-reported snoring). The following equation was used for the calculation of the 4-V: OSAHS $=($ gender*4 $)+(B M I$ category value $)+(B P$ category value $)+($ snoring*4). Gender: females were scored with 0 and males with 1 . BMI category value: BMI $\left(\mathrm{kg} / \mathrm{m}^{2}\right)$ was categorised as $<21.0,21.0-22.9$, $23.0-24.9,25.0-26.9,27.0-29.9, \geq 30$ and values from 1 to 6 were assigned respectively according to Takegami et al. ${ }^{5} \mathrm{BP}$ category value: Blood pressure $(\mathrm{BP})(\mathrm{mmHg})$ was categorised as systolic BP (SBP) $<140$ or diastolic BP (DBP) $<90$, SBP 140-159 or DBP 90-99, SBP160-179 or DBP $100-109, \mathrm{SBP} \geq 180$ or DBP $\geq 110$ and values between 1 and 4 were assigned respectively. ${ }^{5}$ Snoring sometimes or almost never was considered as "no" and was scored with 0 and snoring almost everyday or often was considered as 'yes' and was scored with 1 . We evaluated the cut-offs of $\geq 11$ and $\geq 14$ according to Takegami et al. ${ }^{5}$

All the participants underwent PSG in-laboratory consisting of electroencephalography (EEG), electrooculography (EOG), submental electromyography (EMG), electrocardiography (ECG), snoring (microphone on anterior neck), airflow (by oronasal thermistor and nasal air pressure transducer), body position detection, thoracic and abdominal respiratory effort and oximetry (Alice 5 Diagnostic Sleep System, Philips Respironics). The American Academy of Sleep Medicine (AASM) guidelines were used for PSG manual scoring.' Apnea Hypopnea Index (AHI) was defined as the number of apneas and hypopneas per hour of sleep. Oxygen Desaturation Index (ODI) was defined as the number of desaturations $>4 \%$ divided by the time in bed. ${ }^{10}$ Apneas were defined as the drop of airflow $\geq 90 \%$ of baseline for at least $10 \mathrm{sec}$ and hypopneas as a decrease in airflow of at least $30 \%$ for at least $10 \mathrm{sec}$ with oxygen desaturation of $\geq 4 \%$ from preevent baseline. ${ }^{11}$ The severity of OSAHS was determined by the AHI: $5-14.9$ as mild; $15-29.9$ as moderate; $\geq 30$ as severe. ${ }^{11} \mathrm{AHI} \geq 5$ involves all patients with OSAHS, $\mathrm{AHI} \geq 15$ involves patients with moderate and severe OSAHS and $A H I \geq 30$ patients with severe OSAHS.

\section{Statistical analysis}

SPSS version 17.0 (SPSS Science, Apache Software Foundation, Chicago, IL, USA) was used. The normality of data distribution was tested with Shapiro Wilks. Sensitivity, specificity, positive predictive values (PPV), negative predictive values (NPV), positive and negative likelihood ratios (LR+/LR-) were calculated. Bivariate logistic regression models were used to determine the odds ratio (OR) in predicting OSAHS. The Pearson correlation (for normally distributed) and Spearman correlation (for non normally distributed data) were used to evaluate if there were significant correlations between different variables. The chi-square test was used for categorical variables. Data were presented as mean \pm SD unless otherwise stated. Analysis of variance (ANOVA) with post hoc contrasts by $\mathrm{t}$ tests for normally distributed continuous variables (Bonferroni) was used for the analysis of the differences between group means. For non normally distributed data the Kruskal-Wallis test was used. Tests were two-tailed and $p<0.05$ was accepted as statistically significant. The discriminatory ability of the 4-V for diagnosing OSAHS was evaluated using receiver operating characteristic (ROC) curves.

\section{RESULTS}

From the 1850 patients that visited the Sleep Clinic, $1057(73.8 \%$ males $)$ with a mean age $52 \pm 14$ years, BMI $33 \pm 7 \mathrm{~kg} / \mathrm{m}^{2}$ and AHI $32.7 \pm 26.5$ were included in the study. Seven hundred ninety three patients $(42.8 \%)$ were excluded. Patients who were previously diagnosed with OSAHS $(n=210)$ or already used CPAP $(n=235)$ or had 
another sleep disorder $(\mathrm{n}=32)$ were excluded. Patients with missing data $(\mathrm{n}=316)$ were also excluded. The data that were missing were: snoring in 36 participants, gender in 5, SBP in 36, DBP in 47, BMI in 27, ESS in 42, sleep data in 18 , neck circumference in 23 , hip circumference in 50 and waist circumference in 32 . The characteristics of the subjects involved in the study are presented in Table 1.

Using one way ANOVA (for normally distributed) or Kruskal Wallis (for non normally distributed) or $\mathrm{x}^{2}$ test (for categorical variables) there were significant differences between OSAHS severity and sex, age, BMI, neck and waist circumference, systolic and diastolic BP, snoring, ODI, ESS and 4-V. When post hoc analysis was performed for normally distributed variables (age: $\mathrm{F}=11.74, \mathrm{p}<0,001$, ESS: $\mathrm{F}=31.043, \mathrm{p}<0.001$ ) and Kruskal-Wallis for non normally distributed variables, in different OSAHS severity groups, the statistically significant differences were more limited as shown in Figures 1 and 2.
There were significant differences for BMI, waist and hip circumference between no and mild OSAHS in both men and women $(p<0.005)$ and for all the former and additionally neck circumference between moderate and severe OSAHS for both men and women $(p<0.001)$ (Figure 1).In both genders, there were significant differences between OSAHS severity groups for AHI and ODI $(\mathrm{p}<0.001)$ (Figure 2$)$. The $4-\mathrm{V}$ differed significantly between no and mild $(\mathrm{p}=0.006$ for men and $\mathrm{p}=0.015$ for women) and between moderate and severe OSAHS ( $\mathrm{p}<0.001$ for men and $\mathrm{p}=0.003$ for women), but did not differ between mild and moderate OSAHS in both genders (Figure 2). For BP (that is not included in the former figures) the only statistically significant difference was for Diastolic BP between mild and moderate OSAHS for both men and women $(\mathrm{p}<0.05)$.

In our population, 746 men reported snoring (no OSAHS $=122$, mild OSAHS $=94$, moderate OSAHS $=145$, severe OSAHS $=385$ ) with significant

Table 1: Characteristics of the subjects involved in the study

\begin{tabular}{|c|c|c|c|c|c|c|}
\hline & All & $\mathrm{AHI}<5$ & AHI 5-14.9 & AHI 15-29.9 & $\mathrm{AHI} \geq 30$ & $\mathbf{P}$ \\
\hline Number & 1057 & $208(20 \%)$ & $144(13 \%)$ & $202(19 \%)$ & $503(48 \%)$ & \\
\hline Sex (male/female) ${ }^{* * *}$ & $780 / 277$ & $138 / 70$ & $97 / 47$ & $150 / 52$ & $395 / 108$ & 0.001 \\
\hline Age ( years), (mean $\pm S D)^{*}$ & $52 \pm 14$ & $47.6 \pm 15$ & $50 \pm 14.5$ & $53.6 \pm 14$ & $53.8 \pm 13$ & $<0.001$ \\
\hline BMI $\left(\mathrm{kg} / \mathrm{m}^{2}\right),(\text { mean } \pm S D)^{* *}$ & $33 \pm 7$ & $29 \pm 5.3$ & $31 \pm 5.5$ & $31 \pm 5.5$ & $35.9 \pm 7.3$ & $<0.001$ \\
\hline Neck circumference $(\mathrm{cm})(\text { mean } \pm S D)^{* *}$ & $41.8 \pm 4.3$ & $39.2 \pm 3.7$ & $40.5 \pm 3.9$ & $41.2 \pm 4.5$ & $43.4 \pm 3.9$ & $<0.001$ \\
\hline Waist circumference $(\mathrm{cm})(\text { mean } \pm S D)^{* *}$ & $111 \pm 17$ & $101.2 \pm 13.8$ & $106 \pm 14.3$ & $107.2 \pm 13.5$ & $118.4 \pm 17$ & $<0.001$ \\
\hline Snoring (yes) $)^{* * *}$ & $1005(95 \%)$ & $185(89 \%)$ & $137(95 \%)$ & $194(96 \%)$ & $489(97 \%)$ & 0.001 \\
\hline Diastolic blood pressure, $\mathrm{mmHg},(\text { mean } \pm S D)^{\star *}$ & $80.2 \pm 10.6$ & $78.4 \pm 9.7$ & $77.5 \pm 12$ & $80 \pm 11.5$ & $81.7 \pm 9.8$ & $<0.001$ \\
\hline $\mathrm{AHI}$, events $/ \mathrm{h}^{* *}$ & $32.7 \pm 26.5$ & $2 \pm 1.5$ & $9.6 \pm 3.5$ & $23.4 \pm 4.3$ & $56 \pm 19$ & $<0.001$ \\
\hline ODI/h** & $37.5 \pm 29.2$ & $5.6 \pm 5.4$ & $12.7 \pm 7.3$ & $27.4 \pm 11.2$ & $62 \pm 22.3$ & $<0.001$ \\
\hline ESS, $(\text { mean } \pm S D)^{*}$ & $11.2 \pm 5.4$ & $9.6 \pm 5$ & $9 \pm 4.4$ & $11 \pm 4.8$ & $13 \pm 5.5$ & $<0.001$ \\
\hline$E S S>10^{* * *}$ & $494(47 \%)$ & $70(34 \%)$ & $43(30 \%)$ & $94(46 \%)$ & $287(57 \%)$ & $<0.001$ \\
\hline $4-\mathrm{V},(\text { mean } \pm S D)^{\star *}$ & $13.3 \pm 2.5$ & $12 \pm 2.8$ & $12.8 \pm 2.5$ & $13.2 \pm 2.5$ & $14 \pm 2$ & $<0.001$ \\
\hline $4-V \geq 11^{* * *}$ & $784(74 \%)$ & $123(59 \%)$ & $102(71 \%)$ & $152(75 \%)$ & $407(81 \%)$ & $<0.001$ \\
\hline
\end{tabular}

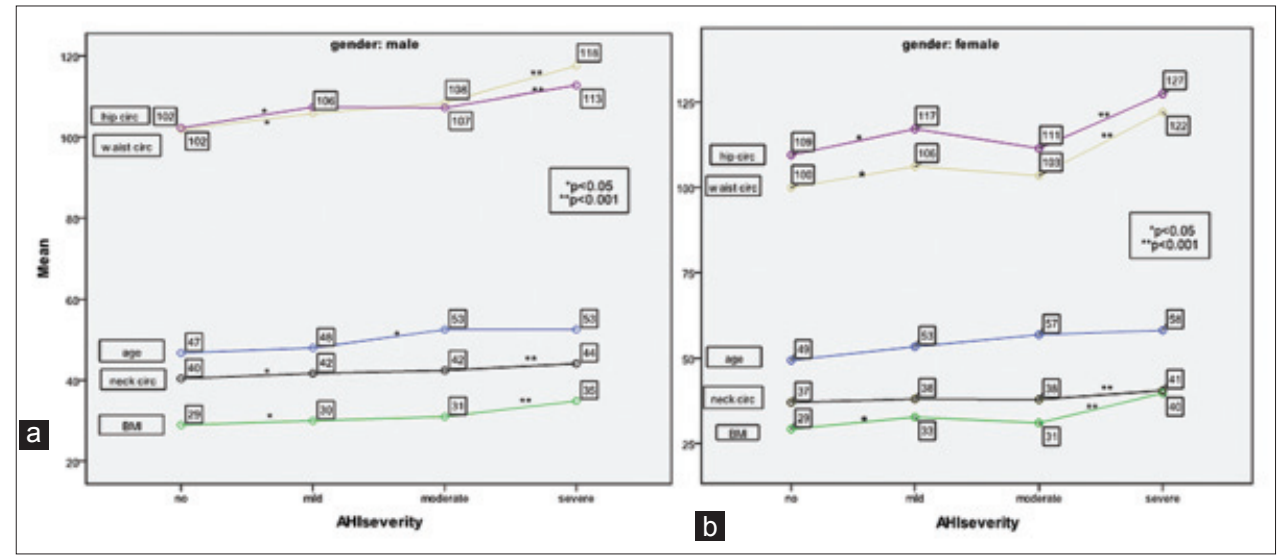

Figure 1: Differences in anthropometric variables between severity groups of OSAHS in both genders (a: male, b: females). circ: circumference, BMI : Body mass index, AHI: Apnea hypopnea index. Post hoc analysis (Bonferroni) was performed for normally distributed variables and KruskalWallis for non normally distributed variables, ${ }^{*} p<0.05,{ }^{* *} p<0.001$ 


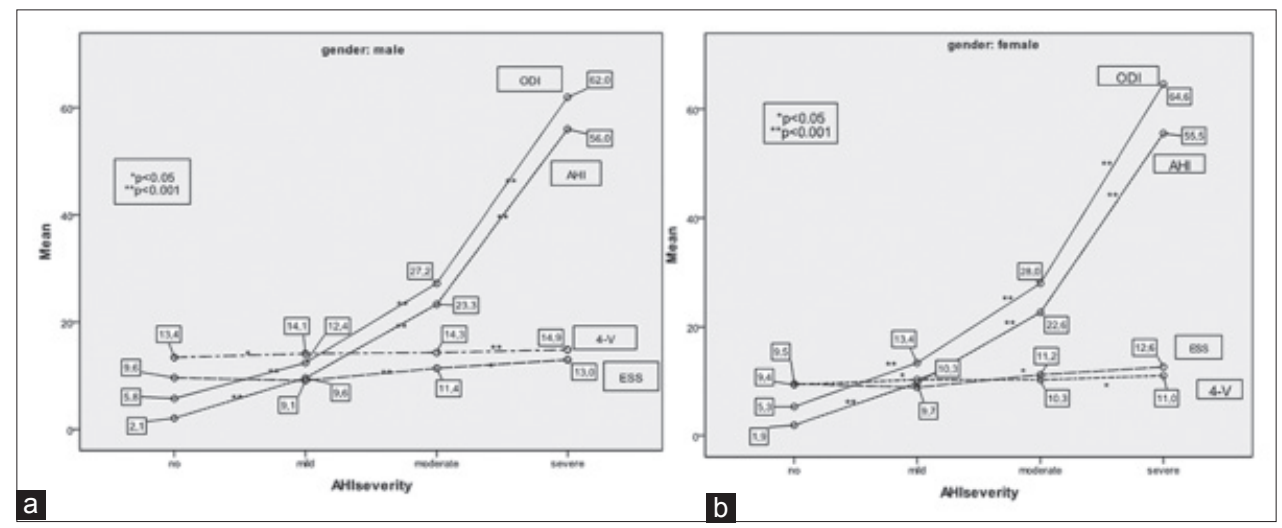

Figure 2: Differences in AHI, ODI, ESS and 4-V between severity groups of OSAHS in both genders (a: male, b: female). AHI: Apnea hypopnea index, ODI: Oxygen desaturation index, ESS: Epworth sleepiness scale, 4-V: 4 Variable screening tool. Post hoc analysis (Bonferroni) was performed for normally distributed variables and Kruskal-Wallis for non normally distributed variables, ${ }^{*} p<0.05,{ }^{* *} p<0.001$

correlation between OSAHS severity and snoring $\left(\mathrm{x}^{2}=21.24, \mathrm{p}<0.001\right)$. However in women 259 reported snoring (no OSAHS $=63$, mild OSAHS $=43$, moderate OSAHS $=49$, severe OSAHS $=104$ ) with no significant correlation between OSAHS severity and snoring.

The predictive values of the ESS were for mild OSAHS: sensitivity $32 \%$, specificity $51 \%$, PPV $9 \%$, NPV $85 \%$, for moderate: sensitivity $44 \%$, specificity $52 \%$, PPV $17 \%$, NPV $81 \%$ and for severe: sensitivity $56 \%$, specificity $63 \%$, PPV $60 \%$, NPV $60 \%$.

A good positive and highly significant correlation was found between the $4-\mathrm{V} \geq 14$ and mild $\left(\mathrm{x}^{2}=16.5, \mathrm{p}<0.001\right)$, moderate $\left(\mathrm{x}^{2}=4.12, \mathrm{p}=0.042\right)$ and severe $\left(\mathrm{x}^{2}=99, \mathrm{p}<0.001\right)$ OSAHS. However for the $4-\mathrm{V} \geq 11$ the only significant correlation was with severe $\left(\mathrm{x}^{2}=23, \mathrm{p}<0.001\right)$ but not mild and moderate OSAHS. The predictive values of different cut-off points of $4-V(\geq 11, \geq 14)$ for the different severity groups of OSAHS are presented in Tables 2, 3 and 4. For a cut-off $\geq 11$ the predictive values were better for $\mathrm{AHI} \geq 5$, apart from sensitivity and NPV that improved for $\mathrm{AHI} \geq 30$ (Table 2). For a cut-off $\geq 14$, the sensitivity was worse than that of a cut-off $\geq 11$, but specificity, PPV, AUC and OR were better (Table 3). Differences in the predicting values of the two 4-V cut-off values for different severity groups and between genders are presented in Table 4 . For $4-\mathrm{V} \geq 11$, sensitivity was high for all severity groups, but specificity was very low in men, but the opposite was found for women with high specificity and low sensitivity(Table 4). For 4-V $\geq 14$ the predictive values improved with the severity of the syndrome for men, but for this cut-off, all women had scores less than 14 (all low probability for OSAHS). Sensitivity was worse but specificity was better (Table 4).

When we calculated the predictive values of $4-\mathrm{V}$ of the patients with positive ESS $(>10)$ for a cut off $\geq 11$ they were: sensitivity $80.1 \%$, specificity $34.7 \%$, PPV $71.4 \%$, NPV $46.2 \%$,

\begin{tabular}{|c|c|c|c|}
\hline & \multicolumn{3}{|c|}{ 4-variable screening tool $\geq 11$} \\
\hline & $\mathrm{AHI} \geq 5$ & $\mathrm{AHI} \geq 15$ & $\mathrm{AHI} \geq 30$ \\
\hline Sensitivity (\%) & 78 & 79 & 81 \\
\hline Specificity (\%) & 40.8 & 36 & 32 \\
\hline PPV $(\%)$ & 84.3 & 71 & 52 \\
\hline NPV $(\%)$ & 31.1 & 46.5 & 65 \\
\hline LR (+)/LR (-) & $1.3 / 0.5$ & $1.2 / 0.6$ & $1.2 / 0.6$ \\
\hline AUC $(95 \% \mathrm{Cl})$ & $0.59(0.55-0.6)$ & $0.58(0.54-0.6)$ & $0.56(0.53-0.6)$ \\
\hline OR (95\% Cl) & $2.4(1.7-3.3)$ & $2.2(1.6-2.9)$ & $2(1.5-2.6)$ \\
\hline
\end{tabular}

AHI: Apnea hypopnea index, PPV: Positive predictive value, NPV: Negative predictive value, LR: Likelihood ratio, AUC: Area under the ROC curve, OR: Odds ratio

Table 3: 4-variable screening tool $\geq 14$ predictive values for different cut-offs of $\mathrm{AHI}$

\begin{tabular}{lccc} 
& \multicolumn{3}{c}{ 4-variable screening tool $\geq \mathbf{1 4}$} \\
\cline { 2 - 4 } & $\mathbf{A H I} \mathbf{2 5}$ & $\mathbf{A H I} \geq \mathbf{1 5}$ & $\mathbf{A H I} \geq \mathbf{3 0}$ \\
\hline Sensitivity (\%) & 50.7 & 55 & 61 \\
Specificity (\%) & 78 & 74.4 & 69 \\
PPV (\%) & 90.3 & 81 & 64 \\
NPV (\%) & 27.9 & 45 & 66 \\
LR (+)/LR (-) & $2.3 / 0.6$ & $2.1 / 0.6$ & $2 / 0.6$ \\
AUC (95\% Cl) & $0.68(0.64-0.7)$ & $0.68(0.64-0.7)$ & $0.66(0.63-0.7)$ \\
OR (95\% Cl) & $3.6(0.55-5.2)$ & $3.5(2.7-4.7)$ & $3.5(2.7-4.6)$ \\
\hline
\end{tabular}

AHI: Apnea hypopnea index, PPV: Positive predictive value, NPV: Negative predictive value, LR: Likelihood ratio, AUC: Area under the ROC curve, OR: Odds ratio

LR(+)/LR(-) 1.22/0.6, OR:2.14 (CI 95\% 1.6-2.9), AUC 0.57 (CI 95\% 0.54-0.61) and for a cut off $\geq 14$ : sensitivity 55\%, specificity $74.5 \%$, PPV $81.5 \%$, NPV 50\%, LR(+)/LR(-): 2.16/0.6, OR 3.6 (CI 95\%, 2.7-4.8), AUC 0.65 (CI 95\% 0.620.68 ) (for $A H I \geq 15)$. The above values did not differ with the predictive values presented in Tables 2 and 3 for $\mathrm{AHI} \geq 15$.

\section{DISCUSSION}

The aim of our study was to validate the 4 Variable Screening Tool in order to evaluate whether it could be 


\begin{tabular}{|c|c|c|c|c|c|c|c|c|c|}
\hline & \multicolumn{9}{|c|}{ 4-variable screening tool $\geq 11$} \\
\hline & \multicolumn{3}{|c|}{ Mild OSAHS } & \multicolumn{3}{|c|}{ Moderate OSAHS } & \multicolumn{3}{|c|}{ Severe OSAHS } \\
\hline & All & 0 & q & All & 0 & q & All & $\hat{0}$ & q \\
\hline Sensitivity (\%) & 74 & 96 & 20.5 & 77.5 & 96.4 & 17 & 81 & 96 & 23 \\
\hline Specificity (\%) & 13 & 6 & 81 & 26 & 6 & 81 & 32 & 8.6 & 84 \\
\hline PPV $(\%)$ & 13 & 12.5 & 16 & 19 & 18.6 & 18 & 52 & 53.2 & 49 \\
\hline NPV (\%) & 87 & 91 & 85.6 & 81.5 & 88.6 & 80 & 65 & 72.2 & 62.3 \\
\hline $\operatorname{LR}(+) / \operatorname{LR}(-)$ & $1 / 1$ & $1 / 0.7$ & $1.1 / 1$ & $1 / 1$ & $1 / 0.6$ & $0.9 / 1$ & $1.2 / 0.6$ & $1.1 / 0.35$ & $1.5 / 0.9$ \\
\hline AUC & 0.5 & 0.5 & 0.5 & 0.5 & 0.5 & 0.5 & 0.56 & 0.53 & 0.54 \\
\hline$(95 \% \mathrm{Cl})$ & $(0.4-0.55)$ & $(0.45-0.6)$ & $(0.4-0.6)$ & $(0.45-0.55)$ & $(0.46-0.57)$ & $(0.4-0.58)$ & $(0.53-0.6)$ & $(0.48-0.57)$ & $(0.46-0.6)$ \\
\hline \multirow[t]{4}{*}{$\begin{array}{l}\text { OR } \\
(95 \% \mathrm{Cl}) \\
\end{array}$} & $\begin{array}{c}0.94 \\
(0.6-1.4)\end{array}$ & $\begin{array}{c}1.5 \\
(0.5-4.3)\end{array}$ & $\begin{array}{c}1.1 \\
(0.5-2.6)\end{array}$ & $\begin{array}{c}1 \\
(0.7-1.44)\end{array}$ & $\begin{array}{c}1.8 \\
(0.7-4.6)\end{array}$ & $\begin{array}{c}0.9 \\
(0.4-0.58)\end{array}$ & $\begin{array}{c}2 \\
(1.5-2.6)\end{array}$ & $\begin{array}{c}3 \\
(1.54-6)\end{array}$ & $\begin{array}{c}1.6 \\
(0.86-2.9)\end{array}$ \\
\hline & \multicolumn{9}{|c|}{ 4-variable screening tool $\geq 14$} \\
\hline & \multicolumn{3}{|c|}{ Mild OSAHS } & \multicolumn{3}{|c|}{ Moderate OSAHS } & \multicolumn{3}{|c|}{ Severe OSAHS } \\
\hline & All & $\hat{0}$ & q & All & $\hat{0}$ & 우 & All & $\sigma^{\lambda}$ & ㅇ \\
\hline Sensitivity (\%) & 30 & 41,5 & 0 & 38.5 & 53 & 0 & 61 & 77.4 & 0 \\
\hline Specificity (\%) & 52 & 35,5 & 100 & 53 & 37 & 100 & 69 & 56.3 & 100 \\
\hline PPV (\%) & 8 & 8 & N/A & 16 & 16 & $\mathrm{~N} / \mathrm{A}$ & 64 & 65.6 & $\mathrm{~N} / \mathrm{A}$ \\
\hline NPV (\%) & 83 & 81.3 & 85.4 & 79 & 78 & 80.4 & 66 & 70 & 60.2 \\
\hline LR (+)/LR (-) & $0.6 / 1.3$ & $0,6 / 1.6$ & $\mathrm{~N} / \mathrm{A} / 1$ & $0.8 / 1.1$ & $0.8 / 1.2$ & $\mathrm{~N} / \mathrm{A} / 1$ & $2 / 0.6$ & $1.8 / 0.4$ & N/A/1 \\
\hline AUC & 0.4 & 0.38 & 0.5 & 0.46 & 0.45 & 0.5 & 0.66 & 0.67 & 0.5 \\
\hline$(95 \% \mathrm{Cl})$ & $(0.36-0.45)$ & $(0.3-0.45)$ & $(0.4-0.6)$ & $(0.4-0.5)$ & $(0.4-0.5)$ & $(0.4-0.6)$ & $(0.63-0.7)$ & $(0.4-0.7)$ & $(0.4-0.6)$ \\
\hline OR & 0.45 & 0.4 & N/A & 0.7 & 0.7 & N/A & 3.5 & 4.5 & N/A \\
\hline$(95 \% \mathrm{Cl})$ & $(0.3-0.66)$ & $(0.25-0.6)$ & & $(0.5-1)$ & $(0.46-1)$ & & $(2.7-4.6)$ & $(3.3-6)$ & \\
\hline
\end{tabular}

OSAHS: Obstructive sleep apnea hypopnea syndrome, AHI: Apnea hypopnea index, PPV: Positive predictive value, NPV: Negative predictive value, LR: Likelihood ratio, AUC: Area under the ROC curve, OR: Odds ratio, N/A: Not applicable

used for the identification of patients at risk of OSAHS in a sleep clinic in Caucasian population. As the incidence of OSAHS is increasing and the financial support is decreasing, it is crucial to assess the patients with the higher risk for OSAHS with an effective screening tool in order to prioritize them for a sleep study.

The 4-V was designed and validated in Asian population ${ }^{5}$ and for a cut-off $\geq 11$, sensitivities $74 \%$ and $95.2 \%$ for respiratory disturbance index $(\mathrm{RDI}) \geq 15$ and $\mathrm{RDI} \geq 30$ respectively and specificities of $66.1 \%$ and $61 \%$ for $\mathrm{RDI} \geq 15$ and $\mathrm{RDI} \geq 30$ respectively were found. ${ }^{5}$ When a cutoff $\geq 14$ was used, sensitivity was worse $(33.3 \%$ and $57.1 \%$ for $\mathrm{RDI} \geq 15$ and $\mathrm{RDI} \geq 30$ respectively), but specificity improved $(94.1 \%$ and $91.3 \%$ for $\mathrm{RDI} \geq 15$ and $\mathrm{RDI} \geq 30$ respectively). ${ }^{5}$ In our study, both cut-offs $\geq 11$ and $\geq 14$ were validated. For a cut-off $\geq 11$, our sensitivities were similar with those of Takegami et al for $\mathrm{AHI} \geq 15$ but lower for $\mathrm{AHI} \geq 30$ and specificities were lower in both groups. For the cut-off $\geq 14$, our sensitivities were slightly better but specificities were lower than those of Takegami ${ }^{5}$ but higher than those of cut-off $\geq 11$. In the study of Silva et a ${ }^{8}$ that analyzed community population from the Sleep Heart Health Study (SHHS) only the cutoff $\geq 14$ was evaluated. In that study, sensitivities were found to be lower $(24.7 \%$ for moderate and $41.5 \%$ for severe OSAHS) than in our study (38.5\% and 61\% respectively) and specificities (93.2\% for both moderate and severe OSAHS) were higher from those of our study (53\% and $69 \%$ respectively), but similar with the specificities of Takegami et $\mathrm{l}^{5}$ for a cut-off $\geq 14$. In our study, 4-V did not differ significantly between mild and moderate OSAHS. However, mild OSAHS was not assessed in the studies of Takegami and Silva et al. ${ }^{5,8}$

When the 4-V was applied to different severity groups of OSAHS (Table 4) sensitivity, specificity, PPV, LR+, AUC raised, but NPV, LR- decreased as the AHI increased. Additionally, for both cut-offs the $4-\mathrm{V}$ had rather low NPV (46.5\% and $45 \%$ respectively) in patients with $\mathrm{AHI} \geq 15$ implying that about half of patients with OSAHS may not be diagnosed.The LR is a parameter used to assess how good a diagnostic test is and has the advantage over sensitivity and specificity because it is less likely to change with the prevalence of the disorder. The LR+ increased and LR- decreased with the severity of OSAHS. In Table 4 for cut-off $\geq 11$, the ORs were not statistically significant (95\% CIs included 1) in mild and moderate OSAHS, but they were significant in severe. For cut-off $\geq 14$, all the ORs were statistically significant. So, as based on our findings, the predictive values of $4-\mathrm{V}$ improved with the severity of OSAHS. Additionally there were significant differences in the predictive values of $4-\mathrm{V}$ between genders, with very high specificity for both cut-offs in women $(100 \%$ for 4 -V $\geq 14$ ) but very low sensitivity. For men, sensitivity 
reached $96 \%$ for cut-off $\geq 11$, but specificity was very low for all severity groups and for cut-off $\geq 14$ the predictive values improved with the severity of the disease with the best predictive values in severe OSAHS group.

Key anatomical risk factors for the development of OSAHS include both obesity and craniofacial morphology, with more severe craniofacial skeletal abnormalities in the non-obese patients. However, obesity and craniofacial skeletal abnormalities may overlap. ${ }^{12} \mathrm{It}$ has been found that compared with Caucasians, Asians have greater restriction in skeletal measurements as a smaller maxilla, a shorter anterior cranial base, smaller and retropositioned mandible. ${ }^{13,14}$ Caucasians are more obese, whereas the cranial base dimensions of Asians are significantly decreased. ${ }^{14}$ In the study of Takegami et al ${ }^{5}$ neck circumference was not found to be an important predictive variable for OSAHS identification. However in Caucasians neck circumference is an important indicator of OSAHS. ${ }^{15,16}$ In our population neck circumference differed significantly as OSAHS severity worsened (Figure 1). This could be a reason of the differences between our findings and those of Takegami et al.

Daytime sleepiness is a common symptom of OSAHS and the ESS is a questionnaire assessing subjective daytime sleepiness. In our population the predictive variables of the ESS for OSAHS diagnosis were similar with those of $4-\mathrm{V} \geq 14$ (Table 4). However ESS is subjective and may underestimate sleepiness, whereas $4-\mathrm{V}$ is more objective. For a cut-off $\geq 11$, the $4-\mathrm{V}$ had better sensitivity, but worse specificity than the ESS. When the $4-\mathrm{V}$ was applied in patients with ESS $>10$ (sleepy patients) the predictive values did not change significantly. So when 4-V and ESS were combined the predictive values did not improve.

For the calculation of $4-\mathrm{V}$ we used the BMI categories as indicated in the study of Takegami that differ from those of the World Health Organization (WHO) BMI classification. ${ }^{17}$ WHO definition for overweight and obesity differ among Asians with BMI cut-offs (23 and $25 \mathrm{~kg} / \mathrm{m}^{2}$, respectively), i.e. lower than the cut-offs used for Caucasians (25 and $30 \mathrm{~kg} / \mathrm{m}^{2}$, respectively). For a similar BMI, Asians have proportionally more fat compared with Caucasians and the BMI level is probably not a good marker of obesity for the comparison between them. ${ }^{18} \mathrm{We}$ used the same cut-offs with Takegami et al and this could be referred as a limitation of our study but our objective was to evaluate the utility of the $4-\mathrm{V}$ as it was developed from Takegami when applied on Caucasian population. When we applied the WHO BMI classification $(\mathrm{BMI}<18.5$, 18.5-24.9, 25-29.9, 30-34.9,35-39.9,>40) the $4 \mathrm{~V}$ differed significantly from the one calculated with Takegami's BMI cut-offs (12 \pm 2.4 vs. $13.3 \pm 2.5, \mathrm{p}<0.001)$. Using WHO BMI classification for cut-off $\geq 11,623$ patients were diagnosed with AHI $>5$ whereas using Takegami's BMI cut-offs 661 . For cut-off $\geq 14$ only 282 patients were diagnosed with AHI $>5$, whereas using Takegami's BMI cut-offs 477 . However, our scope was to evaluate the existing equation from Takegami and not to create a new predictive equation for our population. There are studies for the Greek population with such equations ${ }^{19}$ that involve gender, BMI, neck circumference and excessive daytime sleepiness.

In a meta-analysis, ${ }^{2}$ the STOP and STOP-Bang (S-B), the Berlin questionnaire (BQ), the American Society of Anesthesiologists (ASA) checklist, the Sleep Questionnaire and the sleep disorders questionnaire (SDQ) were evaluated. The ESS was found to be the least accurate and BQ and SDQ the most accurate to screen OSAHS. The S-B was an excellent method for severe OSAHS prediction due to its simplicity. In a systematic review, the Wisconsin and BQ were found to have the highest sensitivity and specificity, ${ }^{4}$ but no definite conclusion was made regarding the most accurate questionnaire for the prediction of OSAHS. Silva et $\mathrm{al}^{8}$ evaluated apart from 4-V, the ESS, Stop and S-B in the general population. They found that the S-B had the highest sensitivity and the 4-V had the highest specificity. The ESS was not as effective to predict OSAHS as Stop, S-B and 4-V.

An important limitation of our study was the fact that it was retrospective and included subjects not from the general population, but from a 'preselected group' of patients visiting a Sleep Clinic. This could be a reason for the difference in the predictive values of $4-\mathrm{V}$ in our population. Additionally there was a significant male predominance in our population as our study was retrospective and the scope was to evaluate $4-\mathrm{V}$ in the unselected population visiting a sleep clinic. It is known that there is a predominance of males in OSAHS in community-based studies (2-3:1) due to the androgenic patterns of body fat distribution with deposition of fat in the trunk and the neck area and possibly due to the effect of sex hormones in the neurologic control of upper airway dilating muscles and ventilation. ${ }^{20,21}$ Also in sleep center-based studies male-to-female ratio of may reach up to 8:1 (in our study 2.8:1) as women often underreport the cardinal symptoms suggestive of of sleep apnea (loud snoring, witnessed apneas, sleepiness) leading to underreferral to sleep centers. This could also explain the marked male predominance. ${ }^{22}$ Another limitation of our study was that the majority of our population reported snoring. Snoring, usually loud, habitual, and bothersome to others, is one of the most common nocturnal symptoms of OSAHS and probably the most common symptom of patients visiting a sleep clinic. In our population most men reported snoring with significant correlation between OSAHS severity and snoring, but women underreported 
snoring with no significant correlation between OSAHS severity and snoring. However, the scope of our study was to evaluate the $4-\mathrm{V}$ in a sleep clinic setting with no selection of the population but in a real life setting.

As a conclusion, in Caucasian general population ${ }^{8}$ and Caucasian population visiting a sleep clinic the sensitivity of the $4-\mathrm{V}$ was low to predict OSAHS. We found that in a Caucasian population visiting a sleep clinic $4-\mathrm{V}$ may miss cases suffering from OSAHS (relatively low sensitivity and NPV) but it has rather good specificity i.e classifying fewer normal persons as high-risk for OSAHS especially for a cutoff $\geq 14$. However the predictive values differed between genders with higher sensitivity for men, but high specificity in women. In sleep centers (high risk for OSAHS) screening tools with high sensitivities should be used in order to avoid missing cases but also sufficient specificity is essential in order to eliminate unnecessary testing. However further studies are needed to determine the most appropriate cut-off point for Caucasian population and to establish a screening strategy including questionnaires with portable devices for sleep apnea detection in the general population.

\section{REFERENCES}

1. Kushida CA, Littner MR, Morgenthaler T, Alessi CA, Bailey D, Coleman J, et al. Practice parameters for the indications for polysomnography and related procedures: an update for 2005 . Sleep 2005; 28:499-521.

2. Ramachandran SK and Josephs LA. A meta-analysis of clinical screening tests for obstructive sleep apnea. Anesthesiology 2009; 110:928-939.

3. Flemons WW, Douglas NJ, Kuna ST, Rodenstein DO and Wheatley J. Access to diagnosis and treatment of patients with suspected sleep apnea. Am J Respir Crit Care Med 2004; 169:668-672.

4. Abrishami A, Khajehdehi A and Chung F. A systematic review of screening questionnaires for obstructive sleep apnea. Can J Anaesth 2010; 57:423-438.

5. Takegami M, Hashino $\mathrm{Y}$, Chin K, Sokejima $\mathrm{S}$ and Kodtani $\mathrm{H}$. Simple four-variable screening tool for identification of patients with sleep-disordered breathing. Sleep 2009; 32:939-948.

6. Johns MW. A new method for measuring daytime sleepiness. Sleep 1991; 14:540-545.

7. Tsara V, Serasli E, Amfilochiou A, Constantinidis $T$ and Christaki P. Greek version of the Epworth Sleepiness Scale.
Sleep Breath 2004; 8:91-95.

8. Silva GE, Vana KD, Goodwin JL, Sherrill DL and Quan SF. Identification of patients with sleep disordered breathing: comparing the four-variable screening tool, STOP, STOPBang, and Epworth Sleepiness Scales. J Clin Sleep Med 2011; 7:467-472.

9. Iber K, Ancoli-Israel S, Chesson AL, Quan SF. In: The AASM manual for the scoring of sleep and associated events. Westchester, IL: American Academy of Sleep Medicine, 2007

10. Ryan PJ1, Hilton MF, Boldy DA, Evans A, Bradbury S, Sapiano S, et al. Validation of British Thoracic Society guidelines for the diagnosis of the sleep apnea/hypoapnea syndrome: can polysomnography be avoided? Thorax 1995; 50:972-975.

11. Sleep-related breathing disorders in adults: Recommendations for syndrome definition and measurement techniques in clinical research. The Report of an American Academy of Sleep Medicine Task Force Sleep 1999; 22:667-689.

12. Sutherland K, Lee RW and Cistulli PA. Obesity and craniofacial structure as risk factors for obstructive sleep apnea: impact of ethnicity. Respirology 2012; 17:213-222.

13. Lee RW, Vasudavan S, Hui DS, Prvan T, Petocz P, Darendeliler MA, et al. Differences in craniofacial structures and obesity in Caucasian and Chinese patients with obstructive sleep apnea. Sleep 2010; 33:1075-1080.

14. Li KK, Kushida C, Powell NB, Riley RW and Guilleminault C. Obstructive sleep apnea syndrome: a comparison between FarEast Asian and white men. Laryngoscope 2000; 110:1689-1693.

15. Caffo B, Diener-West M, Punjabi NM and Samet J. A novel approach to prediction of mild obstructive sleep disordered breathing in a population-based sample: the Sleep Heart Health Study. Sleep 2010; 33:1641-1648.

16. Lam B, Ip MS, Tench E and Ryan CF. Craniofacial profile in Asian and white subjects with obstructive sleep apnea. Thorax 2005; 60:504-510.

17. BMI classification 2006 Global Database on Body Mass Index. WHO. Retrieved May 12, 2014.

18. Genta PR and Lorenzi-Filho G. Sleep apnea in Asians and Caucasians: comparing apples and oranges. Eur Respir J 2011; 37:1537-1538.

19. Bouloukaki I, Kapsimalis F, Mermigkis C, Kryger M, Tzanakis N, Panagou $P$, et al. Prediction of obstructive sleep apnea syndrome in a large Greek population. Sleep Breath 2011; 15:657-664.

20. Young T, Palta M, Dempsey J, Skatrud J, Weber S and Badr S. The occurrence of sleep-disordered breathing among middleaged adults. N Engl J Med 1993; 328:1230-1235.

21. Redline S, Kump K, Tishler PV, Browner I and Ferrette V. Gender differences in sleep disordered breathing in a community-based sample. Am J Respir Crit Care Med 1994; 149:722-726.

22. Ware JC, McBrayer RH and Scott JA. Influence of sex and age on duration and frequency of sleep apnea events. Sleep 2000; 23:165-170.

\section{Authors Contribution:}

AP- Designed, performed the study, analyzed data and wrote the paper; SK, ES, SA, EP and GK- Collected and analyzed data; KF and AP-Analyzed data and were involved in the writing of the paper.

Source of Support: Nil, Conflict of Interest: None. 